\title{
Response to 'Comment on "Excessive Sodium Bicarbonate Infusion May Result in Osmotic Demyelination Syndrome During Treatment of Diabetic Ketoacidosis: A Case Report" by Hsieh et al.'
}

Hui-Chi Hsieh · Shin-Hwar Wu $\cdot$ Chun-Ching Chiu $\cdot$ Keng-Chu Ko (D)

Received: June 3, 2019 / Published online: July 1, 2019

(C) The Author(s) 2019

Keywords: Diabetic ketoacidosis; Hypernatremia; Osmotic demyelination syndrome; Sodium bicarbonate

\section{Dear Editor,}

We appreciate the concise comments and suggestions by Castello and colleagues. They suggested a higher correction factor of serum glucose level and plasma sodium level $\left(P_{\mathrm{Na}}\right)$ be applied for more concise evaluation. Various values had been proposed for the correction factor, such as 1.6, 2.0, 2.4, or even higher [1-3].

We agreed with the suggestions by Castello et al. about the correction factors and careful calculation of osmolytes, but we would also like

Enhanced Digital Features To view enhanced digital features for this article go to https://doi.org/10.6084/ m9.figshare.8294633.

H.-C. Hsieh · S.-H. Wu · C.-C. Chiu · K.-C. Ko (ه) Division of Critical Care, Department of Internal Medicine, Changhua Christian Hospital, Changhua, Taiwan

e-mail: garykou@gmail.com

C.-C. Chiu

Department of Neurology, Changhua Christian Hospital, Changhua, Taiwan

K.-C. Ko

Division of Nephrology, Department of Internal Medicine, Changhua Christian Hospital, Changhua, Taiwan to mention that although we can never overemphasize the importance of estimating the correct $P_{\mathrm{Na}}$, such diversity and complexity may increase the difficulty of decision-making regarding resuscitation. There may be some limitations, such as time limit of resuscitation, extreme changes of vital signs, and so on to prevent clinicians from calculating the osmolytes from each infusion under resuscitation settings. Our main purpose is to highlight the idea that first-line clinicians should follow the treatment guidelines of diabetic ketoacidosis (DKA) $[4,5]$ and restriction of sodium bicarbonate may be the first step of avoiding extraordinary osmolar change.

In our case, the first-line clinicians were initially facing difficult decisions to stabilize the hemodynamic status, and giving large amounts of fluids was naturally the first step. Then severe metabolic acidosis might force the clinician to decide whether to give sodium bicarbonate supplement or even renal replacement therapy. The patient also presented ventricular premature complexes (VPCs) which further interfered with clinical judgement as the VPCs might be life threatening and might result from either acidosis or electrolyte imbalances. To our knowledge, though it is possible, DKA does not typically present with VPCs and shock. The atypical presentation also made it more difficult to follow the guidelines. 
Dr. Bartoli and colleagues performed great work to evaluate the relationships between sodium and water during hyperosmolar hyperglycemic state (HHS), and Dr. Baldrighi and colleagues proposed a concise and detailed method of evaluating fluids and electrolytes in patients with HHS. Further implementation may help clinicians determine the adequate amount of fluid supplements. However, in DKA with life-threatening status, we may need further work to achieve the balance between timely stabilization of vital signs and precise fluid therapy.

\section{ACKNOWLEDGEMENTS}

Funding. No funding or sponsorship was received for the writing of this response letter and no article processing charges were received by the journal for its publication.

Authorship. All named authors meet the International Committee of Medical Journal Editors (ICMJE) criteria for authorship for this article, take responsibility for the integrity of the work as a whole, and have given their approval for this version to be published.

Disclosures. Hui-Chi Hsieh, Shin-Hwar Wu, Chun-Ching Chiu, and Keng-Chu Ko have nothing to disclose.

Compliance with Ethics Guidelines. This response letter is based on previously conducted studies and does not contain any studies with human participants or animals performed by any of the authors.
Peer Review. Please note, contrary to the journal's standard single-blind peer review process, as a letter this article underwent review by one of the journal's Editors-in-Chief.

Open Access. This article is distributed under the terms of the Creative Commons AttributionNonCommercial 4.0 International License (http://creativecommons.org/licenses/by-nc/4.0/), which permits any non-commercial use, distribution, and reproduction in any medium, provided you give appropriate credit to the original author(s) and the source, provide a link to the Creative Commons license, and indicate if changes were made.

\section{REFERENCES}

1. Hillier TA, Abbott RD, Barrett EJ. Hyponatremia: evaluating the correction factor for hyperglycemia. Am J Med. 1999;106(4):399-403.

2. Spasovski G, Vanholder R, Allolio B, et al. Clinical practice guideline on diagnosis and treatment of hyponatraemia. Eur J Endocrinol. 2014;170:G1-G47.

3. Baldrighi M, Sainaghi PP, Bellan M, Bartoli E, Castello LM. Hyperglycemic hyperosmolar state: a pragmatic approach to properly manage sodium derangements. Curr Diabetes Rev. 2018;14(6):534-41.

4. Kitabchi AE, Umpierrez GE, Miles JM, Fisher JN. Hyperglycemic crises in adult patients with diabetes. Diabetes Care. 2009;32(7):1335-43.

5. Dhatariya KK, Vellanki P. Treatment of diabetic ketoacidosis (DKA)/hyperglycemic hyperosmolar state (HHS): novel advances in the management of hyperglycemic crises (UK versus USA). Curr Diabetes Rep. 2017;17(5):33. https://doi.org/10.1007/s11892017-0857-4 